\title{
KLEPTOMANIA: A CASE REPORT IN A NIGERIAN WOMAN
}

Oladele $\mathrm{OT}^{1}$, Abdurahman $\mathrm{AH}^{2}, \mathrm{Abdullahi} \mathrm{I}^{3}$, Madandola $\mathrm{NO}^{1}$

1 Department of clinical service, Federal Neuropsychiatric Hospital, Kware Sokoto, 2 Department of Psychiatry, University College Hospital, Ibadan, Oyo state, 3 Department of Mental

Health Federal Medical Centre, Birnin Kebbi, Kebbi state

Correspondence: Dr. Madandola Nasir O.,

Department of Clinical Services, Federal Neuropsychiatric Hospital,

PMB 2196 Kware, Sokoto State. E-mail: drnasone@yahoo.com

\section{ABSTRACT}

The clinical manifestation of kleptomania also called pathological stealing consists essentially of repeated acts of stealing without any apparent motive of gain to the individual. It results from an intense urge to steal with mounting tension and relief of anxiety afterwards. It falls under the category of habit and impulse disorder of the International Statistical Classification of Diseases, 10th Revision (ICD 10) and can exist primarily without coexisting axis 1 diagnosis or impairment of personality which may result in delayed

\section{INTRODUCTION}

K leptomania has been recognized for more than 150 years as a comparatively rare clinical condition. ${ }^{1}$ The term kleptomania was coined by the French psychiatrists Esquirol and Marc in the 19th century. It has also been a subject of intense controversy and debate ${ }^{3}$ as it remains a poorly understood behavioural disturbance. The exact prevalence is not known since this disorder is rare and also because social stigma discourages patients from seeking treatment. However it is assumed to be about 0.6 percent. The range varies from 3.8 to 24 percent of those arrested for shoplifting ${ }^{6}$.The primary causal factor remains unknown but fatigue, incessant stimulation, and psychic trauma can lower a person's resistance to control impulses ${ }^{6}$. Nevertheless, kleptomania is thought to be more presentation to health facility and poor social support during management. We report clinically diagnosed kleptomania in a 34year old Nigerian female to raise awareness among primary care physicians and mental health providers, especially in the setting of a developing economy.

\section{Key words}

Developing economy, pathological stealing, personality impairment.

frequent in females ${ }^{4}$. Impulsivity is a key feature of kleptomania.

A previous study done by McElroy et al (1991) using 20 patients diagnosed with kleptomania revealed that all 20 patients described irresistible impulses or urges to steal, and tension relief either during or shortly after the act of theft . Although most patients described the impulses as senseless, intrusive, and uncomfortable, and many tried to resist them, half reported pleasurable feelings during the act of theft. All patients reported instances of impulsive stealing, but some also described premeditated stealing, the aim of which was often to relieve the impulses to steal. All patients stated that they considered their stealing to be wrong, and most, but not all, reported guilt or remorse after stealing ${ }^{8}$. 


\section{CASE REPORT}

A 34year old married Nigerian woman from a polygamous setting with large sibship (a group of children from the same parents) devoid of intrafamilial conflict presented to the clinic accompanied by her mother with a 13year history of taking peoples item inappropriately, aimless wandering, aggressive tendencies and spending spree. The illness started in childhood and became worse overtime after marriage with unusual soliciting for loans, claiming to be a contractor and asking people to pay money to her to get certain goods for them. Episodes were usually in the morning with urge to go out and this is usually associated with mounting tension. She usually experience increasing anxiety if resisted and exhibits aggressive outburst if prevented. Going out was usually associated with lying or been deceitful to get money from people. She experiences increasing tension until she gave away the money. She claim she has never spent the money to benefit herself in any- way and used to give more than requested as fare to taxi driver or commercial motorcyclist for services rendered. She denied being under the influence of drugs and was not motivated by prostitution for this behaviour.

There was no history of sustained depression but there were fleeting symptoms of such. She had taken several initiatives to stop the behaviour but was unsuccessful with reinstatement after a maximum of a week. The behaviour had caused embarrassment and impairment in function for her and the family. The family had paid approximately Ten million naira to people she defrauded. The husband recently took her back to the parents but not with the intention of divorce. The onset of illness was during her childhood with perceived self-aggrandisement and penchant to impress people, there is no known family history of similar illness nor was there any significant life event prior to onset of symptoms.

Mental state examination revealed a young woman, appropriately dressed, tearful with remorse, no abnormal movement disorder, calm, cooperative, spontaneous relevant speech and euthymic mood. The Affect was appropriate; thought processes were normal, and no anomalies of perception or cognition. The Neurological, cardiovascular, respiratory examinations and other aspect of physical examination revealed no abnormalities. The last menstrual period was two weeks prior to presentation.

The investigations showed negative pregnancy test, full blood count and serum urea and creatinine were within normal limits. Following voluntary counselling the screening for psychoactive drug use (using the multi-drug screening strips) was negative. Urinalysis showed normal findings. She had a score of 4/52 on Hamilton depression rating scale and a score of $5 / 14$ on the hospital anxiety and depression scale.

A diagnosis of Impulse control disorder; kleptomania was made and she was commenced on tabs Haloperidol $5 \mathrm{mg}$ bid, tabs Neurovite once daily, and Fluoxetine $20 \mathrm{mg}$ daily. Patient was also commenced on a 10 weeks session of cognitive behavioural therapy addressing how to properly redirect her impulses. Family therapy involving father, mother and patient was also carried out in order for them to view her problems as a disease process rather than take a moralistic stand. The husband was invited to address his involvement in management of the patient, although the husband did not respond initially but at about 6weeks into her follow-up, she was accompanied by him to the hospital and the medical team was informed that the family had waded into the imbroglio and they are back together. At her subsequent visits of two weekly intervals her caregiver admitted to marked improvement in her functioning and decline in kleptomanic behaviour. The patient so far has been managed for about 3months.

\section{DISCUSSION}

Kleptomania is a rare disorder in sub-Saharan Africa, probably explaining lack of data on its prevalence in the sub-region. However many cases might have been undetected and probably label as a criminal behaviour. Although it may coexist with depression and anxiety disorders, they are rather fleeting symptoms and do not 
dominate the clinical picture in kleptomaniacs'. ${ }^{6}$ Also, many patients with kleptomania function quite well; others are severely debilitated in social and occupational realms. ${ }^{5}$. The social and family implications may result in divorce and abandonment as families may see it as shameful irresponsibility damaging to collective image. The fact that the husband returned the patient (wife) to her parents and his failure to honour the invitation to participate in the patient's management initially might signify 'abandonment' even in lieu of obvious divorce. Because true kleptomania is rare (as opposed to shoplifting), reports of treatment tend to be individual case descriptions or a short series of cases. Insight-oriented psychotherapy and psychoanalysis have been successful, but depend on patients' motivations. Those who feel guilt and shame may be helped by insight-oriented psychotherapy because of their increased motivation to change their behaviour ${ }^{6}$.

Behaviour therapy, including systematic desensitization, aversive conditioning, and a combination of aversive conditioning and altered social contingencies, has been reported successful, even when motivation was lacking. SSRIs, such as fluoxetine and fluvoxamine appear to be effective in some patients with kleptomania. Case reports also indicated successful treatment with tricyclic drugs, trazodone, lithium, valproate, naltrexone $e^{7}$ and electroconvulsive therapy ${ }^{6}$.

Kleptomania may begin in childhood, although most children and adolescents who steal do not become kleptomaniac adults. The onset of the disorder generally is late adolescence. Women are more likely to present for psychiatric evaluation or treatment than are men but men are more likely to be sent to prison. Men tend to present with the disorder at about 50 years of age and women, at about 35 years of age, this compares well with the age of our patient. The course of the disorder waxes and wanes, but tends to be chronic. Its spontaneous recovery rate is unknown ${ }^{6}$. Serious impairment and complications are usually secondary to being caught, particularly to being arrested. Often, the disorder in no way impairs a person's social or work functioning.
The prognosis with treatment can be good, but few patients come for help of their own accord ${ }^{6}$. Even though our patient's presentation tallies with what obtains in most part of the world, there is a minimal variation in our case from what obtains in most reported cases; deceit to get money (which is prominent in our case) is not reported in most previously studied patients.

This case illustrates the central feature of kleptomania and the resultant family dynamics that results especially in a highly cultural setting of Africa and specifically socioeconomic background of Nigeria.

\section{CONCLUSION}

We have highlighted the clinical features of kleptomania in a 34year old Nigerian woman to raise awareness among primary care and mental health practitioners and enhance early detection and treatment as well as recognizing social limitations that may impair management especially in the setting of a developing economy.

\section{REFERENCES}

1. Marcus J. Goldman, M.D. Am J Psychiatry. 1991 Aug;148(8), : 986-96

2. Farid Ramzi Talih, MD Innov Clin Neurosci 2011;8(10):35-39

3. Elias Aboujoude prim care companion J clin Psychiatry 2001;6(6):156-163

4. Franck J. Baylé, Am J Psychiatry 2003; 160:1509-1513

5. Grant JE, Kim SW. Kleptomania: emerging therapies target mood, impulsive behavior. Current Psychiatry 2002;1(8):45-49.

6. Sadock, Benjamin James; Sadock, Virginia Alcott. Impulse control disorder. In Kaplan and Sadock's Synopsis of Psychiatry: Behavioural Sciences/Clinical Psychiatry.10th ed. Philadelphia: Lippincott Williams \& Wilkins; 2007.pp.773-77.

7. Kim, S.W. (1998). Opioid antagonists in the treatment of impulse-control disorders. Journal of Clinical Psychiatry, 59, 159-64.

8. McElroy, S.L., Pope, H.G., Jr, Hudson, J.I., Keck, P.E., Jr, and White, K.L. (1991). Kleptomania: a report of 20 cases. American Journal of Psychiatry, 148, 652-7 